\title{
COLHEITA E TRANSPORTE FLORESTAL EM PROPRIEDADES RURAIS FOMENTADAS NO ESTADO DO ESPÍRITO SANTO ${ }^{1}$
}

Juliana Lorensi do Canto ${ }^{2}$, Carlos Cardoso Machado ${ }^{3}$, France Maria Gontijo ${ }^{4}$ e Laércio Antônio Gonçalves Jacovine ${ }^{3}$

\begin{abstract}
RESUMO - Este trabalho foi desenvolvido com informações obtidasde 71 proprietários rurais fomentados do Estado do Espírito Santo, responsáveis por 92 contratos de fomento florestal, distribuídos em cinco regiões capixabas, conforme o depósito da empresa fomentadora para a entrega de madeira. O objetivo foi levantar os métodos e equipamentos empregados na colheita e transporte florestal nessas propriedades rurais fomentadas. A área fomentada por contrato variou entre 1,5 e 100,0 ha, sendo de até 30 ha em $84,8 \%$ deles e com relevo montanhoso em 59,8\%. A colheita e o transporte florestais foram terceirizados em 68,5 e 78,2\% dos contratos, respectivamente, e realizados por conta dos proprietários nos demais. Foi constatado que os métodos e equipamentos utilizados na colheita florestal não foram os mesmos nas regiões dos cinco depósitos de entrega de madeira, sendo constatadas, também, diferenças entre os subsistemas utilizados na colheita florestal terceirizada e própria.
\end{abstract}

Palavras-chave: Colheita florestal, transporte florestal, fomento florestal e Estado do Espírito Santo.

\section{FOREST CROP AND WOOD TRANSPORTATION IN FOMENTED FARMS IN THE STATE OF ESPÍRITO SANTO, BRAZIL}

\begin{abstract}
This research was developed with information obtained from 71 fomented farm owners of the Espírito Santo State, Brazil, who were responsible for 92 forest contracts, distributed in five areas of the State, according to the deposit of the fomenter company for wood delivery. The objective was to identify the methods and equipment used in the forest crop and wood transportation in these farms. The area fomented per contract had 1.5 to 100,0 hectares, 84,8\% with up to 30 hectares and 59,8\% with mountain relief. Forest crop and the wood transportation were outsourced in $68,5 \%$ and $78,2 \%$ of the contracts respectively and were carried out by the farm owners in the remaining contracts. It was verified that the methods and equipment used in the forest crop were not the same in the areas of the five deposits of wood delivery, being also verified differences among the subsystems used by the outsourced contractors and the farm owners.
\end{abstract}

Keywords: Forest crop, wood transportation, fomented forest and Espírito Santo State.

\section{INTRODUÇÃO}

A integração dos produtores rurais à base produtiva, via fomento florestal, constitui um instrumento estratégico para suprir a demanda de matéria-prima das indústrias florestais, por aumentar o número de fornecedores de madeira e estimular o mercado regional.
O modelo é viável para a empresa, pois viabiliza a ampliação da base florestal no raio econômico de transporte, sem a imobilização de capital em terras e gastos com infra-estrutura, salários e encargos sociais (ARAÚJO, 1991; CASTRO FILHO, 1991). Além disso, o fomento florestal viabiliza o aproveitamento de áreas degradadas, improdutivas, ociosas, subutilizadas e

\footnotetext{
${ }^{1}$ Recebido em 30.06.06 e aceito para publicação em 12.09.2006.

${ }^{2}$ Programa de Pós-Graduação em Ciência Florestal da Universidade Federal de Viçosa. E-mail: <jlcanto@ terra.com.br>.

${ }^{3}$ Departamento de Engenharia Florestal da Universidade Federal de Viçosa, 36570-000 Viçosa-MG. E-mail: <machado@ufv.br>.

${ }^{4}$ Departamento de Economia Rural da Universidade Federal de Viçosa.
} 
inadequadas à agropecuária, propiciando uma alternativa adicional de renda ao produtor rural proveniente do melhor aproveitamento da propriedade (SIQUEIRA et al., 2004). Contudo, a atividade florestal, em muitos casos, é pioneira em propriedades rurais, tornando necessárias informações e avaliações sobre todo o processo. Isto ocorre pelo fato de os produtores rurais terem pouca tradição e experiência na área de silvicultura (CASTRO FILHO, 1991).

Um estudo realizado por Oliveira (2003), com produtores rurais fomentados no Estado do Espírito Santo, evidenciou que a responsabilidade pela colheita e transporte da madeira é a grande desvantagem do programa de fomento florestal. Segundo o referido autor, na visão do produtor rural fomentado o custo operacional da colheita florestal, o alto risco de acidentes inerente a essas atividades, a falta de conhecimento da operação por parte do produtor e seus familiares e a falta de máquinas e equipamentos adequados na propriedade dificultam a colheita e o transporte florestal.

A colheita florestal é uma atividade complexa, dado o grande número de variáveis que afetam a produtividade e, conseqüentemente, os custos operacionais. Além do pioneirismo dos produtores rurais, deve-se considerar que, na atividade florestal, a colheita e o transporte são as etapas mais importantes do ponto de vista econômico, dada a sua alta participação nos custos finais da madeira posta na indústria, o que pode representar mais de 50\% (BAGIO e STOHR, 1978; REZENDE et al., 1983; MACHADO e LOPES, 2000).

A par dessa realidade, este trabalho teve por objetivo levantar os métodos e equipamentos utilizados na colheita e transporte florestais em propriedades rurais fomentadas no Estado do Espírito Santo. A identificação dos subsistemas utilizados nessas propriedades é condição fundamental para o estabelecimento de bases para a gestão e desenvolvimento dessas atividades.

\section{MATERIAL E MÉTODOS}

\subsection{Amostragem}

A população deste trabalho refere-se aos contratos de fomento estabelecidos entre uma empresa florestal e proprietários rurais do Estado do Espírito Santo, que se encontravam em processo de colheita e transporte da madeira, entre os meses de outubro de 2004 e outubro de 2005. Nesse período, 104 contratos, distribuídos em 22 municípios capixabas, realizaram a colheita florestal e o transporte da madeira até um dos cinco depósitos regionais da empresa. Cada depósito abrangendo, respectivamente, as seguintes regiões: I) Região de Colatina, formada pelos Municípios de Águia Branca, Alto Rio Novo, Baixo Guandu, Colatina, Mantenópolis, Pancas e São Domingos do Norte; II) Região de Marechal Floriano, formada pelos Municípios de Alfredo Chaves, Conceição do Castelo, Domingos Martins e Marechal Floriano; III) Região de Conceição da Barra, formada pelos Municípios de Boa Esperança, Conceição da Barra, Pinheiros e São Mateus; IV) Região de Aracruz, formada pelos Municípios de Aracruz, Ibiraçu, Linhares e Rio Bananal; e V) Região de Santa Teresa, formada pelos Municípios de Itaguaçu, Santa Maria de Jetibá e Santa Teresa.

O número mínimo de contratos a serem amostrados foi calculado segundo a expressão para populações finitas proposta por Richardson (1985):

$$
\mathrm{n}=\frac{\sigma \cdot \mathrm{p} \cdot \mathrm{q} \cdot \mathrm{N}}{\mathrm{E}^{2}(\mathrm{~N}-1)+\sigma^{2} \cdot \mathrm{p} \cdot \mathrm{q}}
$$

em que:

$\mathrm{n}=$ tamanho da amostra;

$\sigma=$ nível de confiança, em número de desvios;

$\mathrm{p}=$ proporção da característica pesquisada no universo, em porcentagem;

$\mathrm{q}=$ proporção do universo que não possui a característica pesquisada, em porcentagem;

$\mathrm{N}=$ tamanho da população;

$\mathrm{E}=$ erro de estimação permitido.

Supôs-se que a proporção da característica pesquisada no universo fosse $50 \%$, ou seja, o caso mais desfavorável para a estimação, pois é aquele em que a amostra deve ser maior. Nesse caso, a proporção do universo que não possui a característica pesquisada é de $50 \%$. Considerando um nível de confiança de $95 \%$, equivalente a dois desvios, e um erro de estimação de 5\%, obteve-se o tamanho mínimo da amostra composto por 83 contratos de fomento florestal. Contudo, foram amostrados 92 contratos, estratificados por região, mantendo-se as proporções de cada estrato da população na amostra. 


\subsection{Obtenção e análise de dados}

Os dados foram obtidos por meio de questionários aplicados aos titulares dos contratos de fomento florestal ou, em alguns casos, no representante ou pessoa ligada ao titular que estava à frente das atividades relacionadas ao contrato. Os 92 contratos amostrados corresponderam a 71 proprietários rurais fomentados, pois houve casos em que um proprietário possuía mais de um contrato ou era responsável por contratos de familiares, sendo estes apenas os titulares legais. Os dados obtidos foram tabulados em planilha eletrônica do Microsoft Excel 2002.

\section{RESULTADOS E DISCUSSÃO}

\subsection{Os contratos de fomento florestal}

O tamanho da área fomentada por contrato variou entre 1,5 e 100,0 hectares, sendo de até 30 hectares em $84,8 \%$ deles e com relevo montanhoso em 59,8\% (Quadro 1).

A maioria dos contratos amostrados nas regiões I e II possuía área de até 30 ha, com relevos ondulado e montanhoso. Na região IV, 85, $1 \%$ dos contratos amostrados possuíam área de até 30 ha, distribuídos em áreas de relevos montanhoso, ondulado e plano. No entanto, a região III foi caracterizada por contratos maiores, sendo que $42,9 \%$ deles possuíam área superior a 30 ha, com relevo plano. A região $\mathrm{V}$ destacou-se das demais por apresentar contratos menores, sendo que $60 \%$ deles possuíam área de até 10 ha e com relevo montanhoso. Acrescenta-se que essa mesma região era composta, predominantemente, por pequenas propriedades rurais, de até 100 ha de área (IBGE, 1998).

As atividades de colheita e transporte florestais foram terceirizadas em $50 \%$ dos contratos da região I; $75,1 \%$ da região II; $100 \%$ da região III; $77,8 \%$ da região IV; e 70\% da região V (Quadro 2). Esse menor porcentual de terceirização na região I pode ter sido pelo fato de que havia poucos prestadores de serviço especializados nessa região.

\subsection{Colheita florestal}

A colheita florestal foi terceirizada em $68,5 \%$ dos contratos, e os principais motivos, expressos pelos proprietários, foram a falta de máquinas e equipamentos adequados, a indisponibilidade de tempo, o custo elevado e a falta de recursos financeiros e a falta de mão-deobra especializada, por ser um trabalho pesado e perigoso e por falta de conhecimento do trabalho (Quadro 3).

Nas regiões dos depósitos III e IV, 66,6 e 46,8\% dos proprietários, respectivamente, terceirizaram a colheita florestal por falta de máquinas e equipamentos. Nessas regiões havia muitos contratos estabelecidos em áreas com relevo plano, evidenciando-se a necessidade desses proprietários em mecanizar a colheita florestal, principalmente as atividades de extração e carregamento e, em especial, nos contratos maiores. Acrescenta-se que a maioria dos prestadores de serviço dessas regiões mecanizava as atividades de colheita florestal.

Quadro 1 - Distribuição porcentual dos contratos por região e por classe de tamanho e relevo da área Table 1 -Percent distribution of contracts per region and per size class and relief of the area

\begin{tabular}{|c|c|c|c|c|c|c|c|}
\hline \multirow[t]{2}{*}{ Relevo } & \multirow{2}{*}{$\begin{array}{l}\text { Classes de } \\
\text { área (ha) }\end{array}$} & \multicolumn{5}{|c|}{ Regiões } & \multirow[t]{2}{*}{ Total } \\
\hline & & $\mathrm{I}$ & II & III & IV & $\mathrm{V}$ & \\
\hline \multirow{4}{*}{ Montanhoso } & $<10$ & 28,2 & 25,0 & $\overline{-}$ & 22,2 & 60,0 & 27,2 \\
\hline & 10 a 29,9 & 28,2 & 62,5 & 14,3 & 3,7 & 30,0 & 26,1 \\
\hline & $>30$ & 12,5 & - & - & 3,7 & 10,0 & 6,5 \\
\hline & Total & 68,9 & 87,5 & 14,3 & 29,6 & 100 & 59,8 \\
\hline \multirow{4}{*}{ Ondulado } & $<10$ & 3,1 & 12,5 & - & 14,8 & - & 7,6 \\
\hline & 10 a 29,9 & 24,9 & - & - & 11,1 & - & 12,0 \\
\hline & $>30$ & 3,1 & - & 14,3 & - & - & 2,2 \\
\hline & Total & 31,1 & 12,5 & 14,3 & 25,9 & - & 21,8 \\
\hline \multirow{4}{*}{ Plano } & $<10$ & - & - & 14,3 & 11,1 & - & 4,3 \\
\hline & 10 a 29,9 & - & - & 14,3 & 22,2 & - & 7,6 \\
\hline & $>30$ & - & - & 42,9 & 11,1 & - & 6,5 \\
\hline & Total & - & - & 71,5 & 44,4 & - & 18,4 \\
\hline
\end{tabular}


Quadro 2 - Distribuição porcentual dos contratos por região e por responsabilidade de execução da colheita e transporte florestais

Table 2 - Percent distribution of contracts per region and responsibility for forest crop and wood transportation

\begin{tabular}{|c|c|c|c|c|c|c|c|}
\hline \multirow[t]{2}{*}{ Colheita } & \multirow[t]{2}{*}{ Transporte } & \multicolumn{5}{|c|}{ Regiões } & \multirow[t]{2}{*}{ Total } \\
\hline & & $\mathrm{I}$ & II & III & IV & $\mathrm{V}$ & \\
\hline Proprietário & Proprietário & 28,1 & 12,5 & - & 14,8 & 10,0 & 17,4 \\
\hline Proprietário & Terceiro & 21,9 & 12,5 & - & 7,4 & 20,0 & 14,1 \\
\hline Terceiro & Terceiro & 46,9 & 56,3 & 100 & 77,8 & 70,0 & 64,1 \\
\hline Terceiro & Proprietário & 3,1 & 18,7 & - & - & - & 4,4 \\
\hline \multicolumn{2}{|c|}{ Total } & 100 & 100 & 100 & 100 & 100 & 100 \\
\hline
\end{tabular}

I) Região de Colatina, II) Região de Marechal Floriano, III) Região de Conceição da Barra, IV) Região de Aracruz e V) Região de Santa Teresa.

Quadro 3 - Principais motivos da terceirização da colheita florestal expressos pelos proprietários, em porcentuais Table 3 - Main reasons for the forest crop outsourcing, expressed by the farm owners, in percentage

\begin{tabular}{|c|c|c|c|c|c|c|}
\hline \multirow[t]{2}{*}{ Motivos } & \multicolumn{5}{|c|}{ Regiões } & \multirow[t]{2}{*}{ Total } \\
\hline & $\mathrm{I}$ & II & III & IV & V & \\
\hline Falta de máquinas e equipamentos & 3,8 & 7,1 & 66,6 & 46,8 & 10,0 & 26,8 \\
\hline Indisponibilidade de tempo & 38,5 & 28,6 & 6,7 & - & 36,7 & 20,0 \\
\hline Custo elevado e falta de recursos & 7,7 & 21,5 & 20,0 & 31,3 & - & 18,5 \\
\hline Falta de mão-de-obra especializada & 23,1 & 28,6 & - & 6,3 & 10,0 & 14,1 \\
\hline Trabalho pesado e perigoso & 26,9 & 7,1 & - & 3,1 & 6,7 & 10,5 \\
\hline Falta de conhecimento do trabalho & - & 7,1 & 6,7 & 12,5 & 36,7 & 10,1 \\
\hline Total & 100 & 100 & 100 & 100 & 100 & 100 \\
\hline
\end{tabular}

I) Região de Colatina, II) Região de Marechal Floriano, III) Região de Conceição da Barra, IV) Região de Aracruz e V) Região de Santa Teresa.

A indisponibilidade de tempo foi o principal motivo alegado por 38,5\% dos proprietários da região I, 28,6\% da região II e $36,7 \%$ da região V. Deve-se considerar que a maioria das propriedades dessas regiões tinha a cafeicultura como principal atividade produtiva, demandando grande quantidade de mão-de-obra (ANUÁRIO... 2005).

Ainda nas regiões II e IV, 21,5 e 31,3\% dos proprietários, respectivamente, terceirizaram a colheita florestal pelo custo elevado e falta de recursos financeiros para aquisição de motosserras e, principalmente, para contratação formal da mão-de-obra (salário e encargos sociais). Além desses, $23,1 \%$ dos proprietários da região I e 28,6\% da região II apontaram a falta de mão-de-obra especializada, enquanto $36,7 \%$ dos proprietários da região $\mathrm{V}$, a falta de conhecimento do trabalho como principal motivo da terceirização.

A colheita florestal nas propriedades rurais fomentadas foi composta pelas etapas de corte (compreendendo as operações de derrubada, desgalhamento e traçamento), extração ou baldeio, empilhamento (quando realizado) e carregamento. Apresenta-se, no Quadro 4, a distribuição porcentual de contratos, conforme os equipamentos e métodos utilizados na realização das etapas da colheita florestal.

R. Árvore, Viçosa-MG, v.30, n.6, p.989-998, 2006
A derrubada das árvores foi realizada, predominantemente, com motosserras. Em apenas 28,6\% dos contratos com colheita terceirizada da região III foi utilizado Harvester. Na operação de derrubada com motosserras foram empregados dois homens, sendo um motosserrista e um ajudante.

O desgalhamento foi realizado com motosserras na maioria dos contratos terceirizados das regiões II, III e IV. Os entrevistados referentes a $43,8 \%$ dos contratos terceirizados da região I e 9,5 da região IV não souberam responder qual equipamento foi utilizado para o desgalhamento. Na região $\mathrm{V}$, verificou-se que em $100 \%$ dos contratos com colheita terceirizada e própria o desgalhamento foi realizado com motosserras, em substituição aos equipamentos manuais. No entanto, em grande parte dos contratos com colheita própria das regiões I, II e IV o desgalhamento foi realizado com machados e facões. Sabe-se que o rendimento operacional no desgalhamento com motosserra é superior ao com o machado. Mas, para que essa seja uma operação produtiva, são necessários operadores bem treinados, o que na maioria das vezes não é o caso dos trabalhadores rurais (SALMERON, 1980). Nessas circunstâncias, deve-se considerar também que o eucalipto destinado à celulose 
possui, em sua maioria, galhos finos e copa concentrada na parte superior da árvore, o que favorece o desgalhamento com instrumentos manuais.

O traçamento dos toretes foi realizado, predominantemente, com motosserras. Em apenas 28,6\% dos contratos com colheita terceirizada da região III foi utilizado Harvester. Quanto ao tamanho dos toretes traçados, nos contratos das regiões I, II e V esses eram de 2,20 $\mathrm{m}$ de comprimento, por exigência da empresa fomentadora, pois, dos depósitos dessas regiões até a fábrica, a madeira era transportada por ferrovias. Nos contratos da região III, os toretes eram de 3,00 m de comprimento, já que do depósito dessa região até a fábrica a madeira era transportada por meio de rodovias. Já na região IV não era exigido comprimento específico dos toretes, dado que os proprietários dessa região entregavam a madeira diretamente na fábrica. Dessa forma, os toretes traçados possuíam 3,00 m de comprimento em $95,2 \%$ dos contratos dessa região com colheita terceirizada e em $83,3 \%$ daqueles com colheita própria. No restante dos contratos, os toretes tinham 2,40 m de comprimento.

Quadro 4 - Distribuição porcentual dos contratos de fomento florestal por equipamentos e métodos utilizados na realização das atividades da colheita florestal

Table 4 - Percent distribution of contracts per equipment and methods used in the forest crop activities

\begin{tabular}{|c|c|c|c|c|c|c|c|c|c|}
\hline \multirow[t]{2}{*}{ Atividades/Regiões } & \multicolumn{4}{|c|}{ Colheita própria } & \multicolumn{5}{|c|}{ Colheita terceirizada } \\
\hline & I & II & IV & $\mathrm{V}$ & I & II & III & IV & $\overline{\mathrm{V}}$ \\
\hline \multicolumn{10}{|l|}{ 1. Corte } \\
\hline \multicolumn{10}{|l|}{ Derrubada } \\
\hline Motosserra & 100 & 100 & 100 & 100 & 100 & 100 & 71,4 & 100 & 100 \\
\hline Harvester & - & - & - & - & - & - & 28,6 & - & - \\
\hline Total & 100 & 100 & 100 & 100 & 100 & 100 & 100 & 100 & 100 \\
\hline \multicolumn{10}{|l|}{ Desgalhamento } \\
\hline Motosserra & 43,8 & 50,0 & 33,3 & 100 & 25,0 & 83,3 & 57,1 & 85,7 & 100 \\
\hline Machado & 31,2 & - & - & - & 18,7 & 16,7 & - & - & - \\
\hline Facão & 18,8 & - & 66,7 & - & 12,5 & - & 14,3 & 4,8 & - \\
\hline Machado e facão & 6,2 & 50,0 & - & - & - & - & - & - & - \\
\hline Harvester & - & - & - & - & - & - & 28,6 & - & - \\
\hline Total & 100 & 100 & 100 & 100 & $56,2 *$ & 100 & 100 & $90,5 *$ & 100 \\
\hline \multicolumn{10}{|l|}{ Traçamento } \\
\hline Motosserra & 100 & 100 & 100 & 100 & 100 & 100 & 71,4 & 100 & 100 \\
\hline Harvester & - & - & - & - & - & - & 28,6 & - & - \\
\hline Total & 100 & 100 & 100 & 100 & 100 & 100 & 100 & 100 & 100 \\
\hline \multicolumn{10}{|l|}{ 2. Extração } \\
\hline Manual/Tombamento & 31,2 & 75,0 & 16,7 & 100 & 43,8 & 91,7 & - & 4,8 & 57,1 \\
\hline Manual/Transporte direto & 68,8 & 25,0 & 66,6 & - & 31,3 & 8,3 & - & 14,3 & 28,6 \\
\hline Trator autocarregável & - & - & 16,7 & - & 18,7 & - & 85,7 & 80,9 & 14,3 \\
\hline Trator com guincho & - & - & - & - & 3,1 & - & 14,3 & - & - \\
\hline Trator com reboque & - & - & - & - & 3,1 & - & - & - & - \\
\hline Total & 100 & 100 & 100 & 100 & 100 & 100 & 100 & 100 & 100 \\
\hline \multicolumn{10}{|l|}{ 3. Empilhamento } \\
\hline Realizado & 25,0 & 50,0 & 16,7 & - & 43,8 & 83,3 & 28,6 & 61,9 & 57,1 \\
\hline Não realizado & 62,5 & 50,0 & 83,3 & 100 & 50,0 & 16,7 & 42,8 & 38,1 & 42,9 \\
\hline Eventualmente realizado & 12,5 & - & - & - & 6,2 & - & 28,6 & - & - \\
\hline Total & 100 & 100 & 100 & 100 & 100 & 100 & 100 & 100 & 100 \\
\hline \multicolumn{10}{|l|}{ 4. Carregamento } \\
\hline Manual & 100 & 100 & 83,3 & 100 & 87,5 & 100 & 14,3 & 19,0 & 100 \\
\hline Mecanizado & - & - & 16,7 & - & 12,5 & - & 85,7 & 81,0 & - \\
\hline Total & 100 & 100 & 100 & 100 & 100 & 100 & 100 & 100 & 100 \\
\hline
\end{tabular}

I) Região de Colatina, II) Região de Marechal Floriano, III) Região de Conceição da Barra, IV) Região de Aracruz e V) Região de Santa Teresa. *Os proprietários referentes aos contratos restantes não souberam responder qual o equipamento foi utilizado pelos prestadores de serviço. 
Nos contratos com colheita terceirizada das regiões III e IV foram utilizados, predominantemente, métodos de extração mecanizados, principalmente por meio de trator autocarregável, ou seja, equipado com grua. Salienta-se que a maioria dos contratos dessas regiões possuía área de relevo plano ou ondulado, o que propiciava a mecanização dessa atividade. No entanto, em grande parte dos contratos terceirizados das regiões I, II e V foi realizada a extração manual, com tombamento dos toretes ou transporte direto. Cabe explicar que o tombamento consiste no lançamento dos toretes no sentido da declividade favorável do terreno, de forma que esses cheguem até as proximidades da estrada florestal (MACHADO e SOUZA JUNIOR, 1991). Esse método foi utilizado nos contratos com área de relevo montanhoso. Entretanto, o transporte direto foi utilizado em condições topográficas favoráveis, que possibilitaram a entrada do caminhão do transporte principal no plantio.

Nos contratos com colheita própria, a extração foi, predominantemente, manual. Em apenas 16,7\% dos contratos da região IV a extração foi realizada com trator autocarregável. O menor grau de mecanização da extração, nos contratos em que a colheita foi executada pelos proprietários, é facilmente justificável devido aos altos custos de aquisição de equipamentos específicos, como Skidder e Forwarder, que se tornariam economicamente inviáveis em pequenas áreas, principalmente devido aos custos de depreciação e juros (MINETTE et al., 2004; BIRRO et al., 2002).

O empilhamento da madeira nas margens das estradas, à espera do transporte, foi realizado na maior parte dos contratos terceirizados das regiões II, IV e V. Entretanto, em grande parte dos contratos terceirizados das regiões I e II não foi executado o empilhamento. Dos contratos com colheita própria, a madeira foi empilhada em apenas $25 \%$ da região I, $50 \%$ da região II e $16,7 \%$ da região IV. Nos contratos em que o empilhamento não foi realizado, a madeira permaneceu na área de plantio até o momento de ser transportada, quando então foi realizada a extração. Em caso de chuva ou qualquer outro imprevisto no transporte principal da madeira, essa situação pode vir a prejudicar a regeneração por brotação do eucalipto.

O carregamento da madeira para os veículos de transporte foi manual em $100 \%$ dos contratos com colheita terceirizada das regiões II e V e 87,5\% da região I. Mas o carregamento foi mecanizado em $85,7 \%$ dos contratos terceirizados da região III e $81 \%$ da região IV. Nos contratos com colheita própria, o carregamento foi mecanizado em somente $16,7 \%$ dos contratos da região IV e nos demais contratos, manual.

O principal entrave da colheita terceirizada, na percepção dos proprietários das regiões I, III e V, está relacionado com as condições climáticas, principalmente em referência às chuvas ocorridas durante a atividade (Quadro 5). Além disso, boa parte dos proprietários das regiões I, IV e V, que terceirizaram a colheita, apontaram a falta de mão-de-obra especializada. Destacase que, dos proprietários que terceirizaram a colheita, $7,7 \%$ da região I, $6,6 \%$ da região III e $6,2 \%$ da região IV consideraram como entrave o relacionamento com os prestadores de serviço contratados, sobretudo em referência ao controle da produção e ao volume de madeira transportado.

Quadro 5 - Principais entraves da colheita florestal identificados pelos proprietários rurais

Table 5 - Main problems of forest crop, identified by the farm owners

\begin{tabular}{|c|c|c|c|c|c|c|c|c|c|}
\hline \multirow[t]{2}{*}{ Entraves } & \multicolumn{4}{|c|}{ Colheita própria } & \multicolumn{5}{|c|}{ Colheita terceirizada } \\
\hline & $\mathrm{I}$ & II & IV & $\mathrm{V}$ & $\mathrm{I}$ & II & III & IV & $\mathrm{V}$ \\
\hline$\overline{\text { Condições climáticas }}$ & 7,1 & 50,0 & - & 50,0 & 46,1 & 14,3 & 66,8 & 12,5 & $\overline{60,0}$ \\
\hline Falta de mão-de-obra & 25,0 & 12,5 & - & 50,0 & 23,1 & - & - & 12,5 & 20,0 \\
\hline Falta de máquinas e equipam. & - & - & 20,0 & - & - & - & - & 18,8 & - \\
\hline Relevo montanhoso & 7,1 & 12,5 & - & - & - & 14,3 & 6,6 & 6,2 & - \\
\hline Relacionamento com terceiros & - & - & - & - & 7,7 & - & 6,6 & 6,2 & - \\
\hline Trabalho pesado e perigoso & 17,9 & 25,0 & 60,0 & - & - & - & - & 12,5 & - \\
\hline Custo elevado & - & - & - & - & - & - & - & 6,2 & - \\
\hline Não houve nenhum entrave & 42,9 & - & 20,0 & - & 23,1 & 71,4 & 20,0 & 25,1 & 20,0 \\
\hline Total & 100 & 100 & 100 & 100 & 100 & 100 & 100 & 100 & 100 \\
\hline
\end{tabular}

I) Região de Colatina, II) Região de Marechal Floriano, III) Região de Conceição da Barra, IV) Região de Aracruz e V) Região de Santa Teresa.

R. Árvore, Viçosa-MG, v.30, n.6, p.989-998, 2006 
Dos proprietários que realizaram a colheita por conta própria, $50 \%$ das regiões II e $\mathrm{V}$ consideraram as condições climáticas o principal entrave da atividade, principalmente em referência às chuvas ocorridas, sendo justificado pela predominância, nessas regiões, de áreas com relevo montanhoso. Além disso, a falta de mão-de-obra especializada foi apontada por $25 \%$ dos proprietários da região I, $12,5 \%$ da região II e $50 \%$ da região $\mathrm{V}$ como o principal entrave da atividade. Ainda, $60 \%$ dos proprietários da região IV consideraram a colheita um trabalho pesado e perigoso, e $20 \%$ apontaram a falta de máquinas e equipamentos como principais entraves.

Na colheita florestal própria foi usada mão-deobra contratada na maioria dos contratos das regiões I, II e IV. Contudo, houve emprego de mão-de-obra familiar na maioria dos contratos da região $\mathrm{V}$, sendo que não foi utilizada mão-de-obra contratada (Quadro 6). Essa região destacou-se das demais por apresentar, predominantemente, pequenos contratos de fomento florestal e ser caracterizada por pequenas propriedades rurais.

A grande maioria dos proprietários que realizaram a colheita florestal por conta própria alegou ter tido dificuldade em contratar mão-de-obra especializada, sendo $100 \%$ das regiões I e IV e 66,7\% da região II. Na região V, como não foi empregada mão-deobra contratada, essa questão não foi apresentada aos proprietários. Nesse sentido, acrescenta-se que a mão-de-obra treinada influencia diretamente o rendimento do sistema de colheita.

\subsection{Transporte florestal}

O transporte da madeira da área de colheita até o depósito de entrega foi terceirizado em $68,8 \%$ dos contratos da região I e da região II, $100 \%$ da região III, $85,2 \%$ da região IV e $90 \%$ da região V. Segundo os proprietários, o principal motivo foi a falta de veículo próprio.

O transporte foi realizado, predominantemente, por caminhões de dois e três eixos (Quadro 7). Em média, os caminhões de dois eixos têm capacidade para 18 a 20 estéreos de madeira e os de três eixos, de 25 a 28 estéreos.

A distância média calculada da área dos contratos até o respectivo depósito de entrega da madeira foi de 74,6 km na região I, $28,6 \mathrm{~km}$ na II, $33,4 \mathrm{~km}$ na III, $49,1 \mathrm{~km}$ na IV e $34,7 \mathrm{~km}$ na região V. Aregião I apresentou maior distância média de transporte, sendo justificada pelo maior número de municípios abrangidos por ela.

Quadro 6 - Tipo de mão-de-obra empregada na colheita florestal própria, em porcentuais

Table 6 - Type of labor employed by the farmers in the forest crop, in percentage

\begin{tabular}{ccccc}
\hline Tipo de Mão-de-Obra & \multicolumn{4}{c}{ Regiões } \\
\cline { 2 - 5 } & I & II & IV & V \\
\hline Contratada & 65,6 & 75,0 & 83,3 & - \\
Familiar & 15,6 & 25,0 & 16,7 & 66,7 \\
Meeiros & 6,3 & - & - & 33,3 \\
Vizinhos & 12,5 & - & - & - \\
\hline Total & 100 & 100 & 100 & 100 \\
\hline
\end{tabular}

I) Região de Colatina, II) Região de Marechal Floriano, IV) Região de Aracruz e V) Região de Santa Teresa.

Quadro 7 - Tipos de caminhão utilizados no transporte florestal, em porcentual Table 7 - Types of trucks used in wood transportation, in percentage

\begin{tabular}{|c|c|c|c|c|c|c|c|c|c|}
\hline \multirow[t]{2}{*}{ Tipo de Caminhões/Regiões } & \multicolumn{4}{|c|}{ Transporte Próprio } & \multicolumn{5}{|c|}{ Transporte Terceirizado } \\
\hline & $\mathrm{I}$ & II & IV & $\mathrm{V}$ & $\mathrm{I}$ & II & III & IV & $\mathrm{V}$ \\
\hline Dois eixos & 40,0 & 20,0 & - & 100 & 18,2 & 18,2 & - & - & 88,9 \\
\hline Dois e três eixos & 40,0 & 80,0 & - & - & 22,7 & 63,6 & 28,6 & - & 11,1 \\
\hline Três eixos & 20,0 & - & 100 & - & 36,4 & 18,2 & 57,1 & 26,1 & - \\
\hline Dois e três eixos e articulados & - & - & - & - & 22,7 & - & - & - & - \\
\hline Três eixos e articulados & - & - & - & - & - & - & - & 39,1 & - \\
\hline Articulados & - & - & - & - & - & - & - & 30,4 & - \\
\hline Bitrem - & - & - & - & - & - & 14,3 & - & - & \\
\hline Total & 100 & 100 & 100 & 100 & 100 & 100 & 100 & $95,6^{*}$ & 100 \\
\hline
\end{tabular}

I) Região de Colatina, II) Região de Marechal Floriano, III) Região de Conceição da Barra, IV) Região de Aracruz e V) Região de Santa Teresa. *Os proprietários referentes aos contratos restantes não souberam responder qual o tipo de veículo foi utilizado pelos prestadores de serviço. 


\section{CONCLUSÕES}

- A colheita e transporte florestais foram terceirizados na maioria dos contratos de fomento florestal, principalmente por falta de máquinas e equipamentos, indisponibilidade de tempo, custo elevado e falta de recursos financeiros e de mão-de-obra especializada.

- Foram constatadas diferenças nos métodos e equipamentos utilizados na colheita florestal nas regiões dos cinco depósitos de entrega de madeira, sendo constatadas, também, diferenças entre os subsistemas utilizados nas colheitas florestais terceirizada e própria.

- A motosserra foi o principal equipamento utilizado nas operações de derrubada, desgalhamento e traçamento, tanto pelos proprietários quanto pelos prestadores de serviço.

- A extração e o carregamento foram manuais na colheita florestal própria. Na colheita terceirizada, foi constatado maior grau de mecanização dessas atividades nas regiões com contratos maiores e área de relevo favorável, sendo que o trator autocarregável foi o principal equipamento de extração e carregamento. Entretanto, em algumas regiões o relevo foi fator limitante para a mecanização.

- O transporte florestal foi realizado, principalmente, por caminhões de dois e três eixos.

- Evidenciou-se a necessidade de capacitação e treinamento de mão-de-obra para a colheita florestal, tendo em vista que os proprietários consideraram a falta de mão-de-obra especializada como um dos principais motivos da terceirização e entraves da colheita florestal. Isso foi confirmado pela maioria dos proprietários que realizaram a atividade por conta própria e que tiveram dificuldade para contratar mão-de-obra qualificada.

\section{AGRADECIMENTOS}

Ao Conselho Nacional de Desenvolvimento Científico e Tecnológico - CNPq e à Empresa Aracruz Celulose, pelo apoio disponibilizado.

\section{REFERÊNCIAS BIBLIOGRÁFICAS}

ANUÁRIO DO ESPÍRITO SANTO. Vitória: A Gazeta, 2005. 312 p.

R. Árvore, Viçosa-MG, v.30, n.6, p.989-998, 2006
ARAÚJO, J.C.A. O projeto de fomento florestal da Aracruz Celulose S.A. In: SEMINÁRIO SOBRE ASPECTOS ECONÔMICOS, SOCIAIS EAMBIENTAIS DOFOMENTOFLORESTAL, 1990, Belo Horizonte. Anais... Viçosa, MG: UFV/DEF/SIF, 1991. p. 70-76.

BAGIO, A.J.; STOHR, G.W.D. Resultados preliminares de um levantamento dos sistemas de exploração usados em florestas implantadas no sul do Brasil. Revista Floresta, v. 9, n. 2, p. 76-96, 1978.

BIRRO, M.H.B. et al. Avaliação técnica e econômica da extração de madeira de eucalipto com “Track-Skidder” em região montanhosa. Revista Árvore, v. 26, n. 5, p. 525-532, 2002.

CASTRO FILHO, F.P. Política de fomento florestal do estado de Minas Gerais. In: SEMINÁRIO SOBRE ASPECTOS ECONÔMICOS, SOCIAIS EAMBIENTAIS DOFOMENTOFLORESTAL, 1990, Belo Horizonte. Anais... Viçosa, MG: UFV/DEF/SIF, 1991.p. 18-28.

INSTITUTO BRASILEIRO DE GEOGRAFIA E estatís TICA - IBGE. Censo Agropecuário 1995/1996. Rio de Janeiro: 1998. 211 p. (Espírito Santo, 17).

MACHADO, C.C.; LOPES, E.S. Análise da influência do comprimento de toras de eucalipto na produtividade e custo da colheita e transporte florestal. Cerne, v. 6, n. 2, p. 124-129, 2000.

MACHADO, C.C.; SOUZA JUNIOR, H.S. Otimização da produtividade e do custo do tombamento manual de toretes de madeira em regiões montanhosas. Revista Árvore, v. 15, n. 2, p. 164-172, 1991.

MINETTE, L.J. et al. Análise técnica e econômica do Forwarder em três subsistemas de colheita de florestas de eucalipto. Revista Árvore, v. 28, n. 1, p. 91-97, 2004.

OLIVEIRA, P.R.S. Diagnóstico e indicadores de sustentabilidade em fomento florestal no estado do Espírito Santo. 2003. 127 f. Dissertação (Mestrado em Ciência Florestal) - Universidade Federal de Viçosa, Viçosa, MG, 2003.

REZENDE, J.L.P.; PEREIRA, A.R.; OLIVEIRA, A.D. Espaçamento ótimo para a produção de madeira. Revista Árvore, v. 7, n. 1, p. 30-43, 1983. 
RICHARDSON, R. J. Pesquisa social: métodos e técnicas. São Paulo: Altas, 1985. 287 p.

SALMERON, A. Mecanização da exploração florestal. Piracicaba: IPEF, 1980. 10 p. (Circular Técnica, 88).
SIQUEIRA, J.D.P. et al. Estudo ambiental para os programas de fomento florestal da Aracruz Celulose S.A. e extensão florestal do Governo do Estado do Espírito Santo. Revista Floresta, n. 11, p. 3-67, 2004. Edição Especial. 